\title{
Approach to Leg Edema of Unclear Etiology
}

\author{
John W. Ely, MD, MSPH, Jerome A. Osheroff, MD, M. Lee Chambliss, MD, MSPH, and \\ Mark H. Ebell, MD, MS
}

A common challenge for primary care physicians is to determine the cause and find an effective treatment for leg edema of unclear etiology. We were unable to find existing practice guidelines that address this problem in a comprehensive manner. This article provides clinically oriented recommendations for the management of leg edema in adults. We searched on-line resources, textbooks, and MEDLINE (using the MeSH term, "edema") to find clinically relevant articles on leg edema. We then expanded the search by reviewing articles cited in the initial sources. Our goal was to write a brief, focused review that would answer questions about the management of leg edema. We organized the information to make it rapidly accessible to busy clinicians. The most common cause of leg edema in older adults is venous insufficiency. The most common cause in women between menarche and menopause is idiopathic edema, formerly known as "cyclic" edema. A common but under-recognized cause of edema is pulmonary hypertension, which is often associated with sleep apnea. Venous insufficiency is treated with leg elevation, compressive stockings, and sometimes diuretics. The initial treatment of idiopathic edema is spironolactone. Patients who have findings consistent with sleep apnea, such as daytime somnolence, load snoring, or neck circumference $>17$ inches, should be evaluated for pulmonary hypertension with an echocardiogram. If time is limited, the physician must decide whether the evaluation can be delayed until a later appointment (eg, an asymptomatic patient with chronic bilateral edema) or must be completed at the current visit (eg, a patient with dyspnea or a patient with acute edema $[<72$ hours]). If the evaluation should be conducted at the current visit, the algorithm shown in Figure 1 could be used as a guide. If the full evaluation could wait for a subsequent visit, the patient should be examined briefly to rule out an obvious systemic cause and basic laboratory tests should be ordered for later review (complete blood count, urinalysis, electrolytes, creatinine, blood sugar, thyroid stimulating hormone, and albumin). (J Am Board Fam Med 2006;19:148-60.)

Edema is defined as a palpable swelling caused by an increase in interstitial fluid volume. The most likely cause of leg edema in patients over age 50 is venous insufficiency. Venous insufficiency affects up to $30 \%$ of the population, ${ }^{1,2}$ whereas heart failure affects only approximately $1 \% .^{3,4}$ The most likely cause of leg edema in women under age 50 is idiopathic edema, formerly known as cyclic ede-

Submitted 18 April 2005; revised 1 June 2005; accepted 6 June 2005.

From the Department of Family Medicine, University of Iowa Carver College of Medicine, Iowa City, IA (JWE); Thomson MICROMEDEX, Greenwood Village, CO (JAO); Moses Cone Hospital Family Medicine Residency, Greensboro, NC (MLC); and Department of Family Practice, Michigan State University, East Lansing, MI (MHE).

Conflict of interest: none declared.

Corresponding author: John W. Ely, MD, MSPH, University of Iowa College of Medicine, Department of Family Medicine, 200 Hawkins Drive, 01291-D PFP, Iowa City, IA 52242 (E-mail: john-ely@uiowa.edu). ma. ${ }^{5}$ Most patients can be assumed to have one of these diseases unless another cause is suspected after a history and physical examination. However, there are at least 2 exceptions to this rule: pulmonary hypertension and early heart failure can both cause leg edema before they become clinically obvious in other ways.

\section{Classification}

There are 2 types of leg edema: venous edema and lymphedema. Venous edema consists of excess lowviscosity, protein-poor interstitial fluid resulting from increased capillary filtration that cannot be accommodated by a normal lymphatic system. ${ }^{6}$ Lymphedema consists of excess protein-rich interstitial fluid within the skin and subcutaneous tissue resulting from lymphatic dysfunction. ${ }^{7}$ A third type, lipidema, is more accurately considered a form of fat maldistribution rather than true edema. ${ }^{8}$ 
Table 1. Common Causes of Leg Edema in the United States

\begin{tabular}{|c|c|c|c|}
\hline \multicolumn{2}{|c|}{ Unilateral } & \multicolumn{2}{|c|}{ Bilateral } \\
\hline Acute ( $<72$ hours) & Chronic & Acute ( $<72$ hours) & Chronic \\
\hline \multirow[t]{9}{*}{ Deep vein thrombosis } & Venous insufficiency & & Venous insufficiency \\
\hline & & & Pulmonary hypertension \\
\hline & & & Heart failure \\
\hline & & & Idiopathic edema \\
\hline & & & Lymphedema \\
\hline & & & Drugs \\
\hline & & & Premenstrual edema \\
\hline & & & Pregnancy \\
\hline & & & Obesity \\
\hline
\end{tabular}

\section{Diagnosis}

The differential diagnosis of edema is presented in Tables 1 through 3 . Figures 1 through 5 provide an algorithm for diagnostic evaluation.

\section{History}

Key elements of the history include

- What is the duration of the edema (acute $[<72$ hours] vs. chronic)? If the onset is acute, deep vein thrombosis should be strongly considered. ${ }^{6,9-11}$ The 72-hour cutoff is commonly cited $^{9-11}$ but arbitrary and not well supported with evidence. Deep vein thrombosis should be con- sidered in patients presenting after 72 hours with otherwise consistent findings.

- Is the edema painful? Deep vein thrombosis and reflex sympathetic dystrophy are usually painful. ${ }^{10,12}$ Chronic venous insufficiency can cause low-grade aching. Lymphedema is usually painless. ${ }^{9,10,12-15}$

- What drugs are being taken? Calcium channel blockers, prednisone, and anti-inflammatory drugs are common causes of leg edema. ${ }^{9,14,16,17}$ Other drugs that may cause edema are listed in Table 4.

- Is there a history of systemic disease (heart, liver, or kidney disease)?

- Is there a history of pelvic/abdominal neoplasm or radiation?

Table 2. Less Common Causes of Leg Edema in the United States

\begin{tabular}{|c|c|c|c|}
\hline \multicolumn{2}{|c|}{ Unilateral } & \multicolumn{2}{|c|}{ Bilateral } \\
\hline Acute (<72 hours) & Chronic & Acute ( $<72$ hours) & Chronic \\
\hline Ruptured Baker's cyst & $\begin{array}{l}\text { Secondary lymphedema (tumor, } \\
\text { radiation, surgery, bacterial } \\
\text { infection) }\end{array}$ & Bilateral deep vein thrombosis & $\begin{array}{l}\text { Renal disease (nephrotic } \\
\text { syndrome, glomerulonephritis) }\end{array}$ \\
\hline $\begin{array}{l}\text { Ruptured medial head of } \\
\text { gastrocnemius }\end{array}$ & $\begin{array}{l}\text { Pelvic tumor or lymphoma } \\
\text { causing external pressure on } \\
\text { veins }\end{array}$ & $\begin{array}{l}\text { Acute worsening of systemic cause } \\
\text { (heart failure, renal disease) }\end{array}$ & Liver disease \\
\hline \multirow[t]{8}{*}{ Compartment syndrome } & Reflex sympathetic dystrophy & & $\begin{array}{l}\text { Secondary lymphedema } \\
\text { (secondary to tumor, radiation, } \\
\text { bacterial infection, filariasis) }\end{array}$ \\
\hline & & & $\begin{array}{l}\text { Pelvic tumor or lymphoma } \\
\text { causing external pressure }\end{array}$ \\
\hline & & & Dependent edema \\
\hline & & & Diuretic-induced edema \\
\hline & & & Dependent edema \\
\hline & & & Preeclampsia \\
\hline & & & Lipidema $^{8}$ \\
\hline & & & Anemia \\
\hline
\end{tabular}


Table 3. Rare Causes of Leg Edema in the United States

\begin{tabular}{|c|c|c|c|}
\hline \multicolumn{2}{|r|}{ Unilateral } & \multicolumn{2}{|r|}{ Bilateral } \\
\hline Acute ( $<72$ hours) & Chronic & Acute ( $<72$ hours) & Chronic \\
\hline & $\begin{array}{l}\text { Primary lymphedema (congenital } \\
\text { lymphedema, lymphedema praecox, } \\
\text { lymphedema tarda) }\end{array}$ & & $\begin{array}{l}\text { Primary lymphedema (congenital } \\
\text { lymphedema, lymphedema praecox, } \\
\text { lymphedema tarda) }\end{array}$ \\
\hline & Congenital venous malformations & & $\begin{array}{l}\text { Protein losing enteropathy, malnutrition, } \\
\text { malabsorption }\end{array}$ \\
\hline & $\begin{array}{l}\text { May-Thurner syndrome (iliac-vein } \\
\text { compression syndrome) }^{51}\end{array}$ & & Restrictive pericarditis \\
\hline & & & Restrictive cardiomyopathy \\
\hline & & & Beri Beri \\
\hline & & & Myxedema \\
\hline
\end{tabular}

- Does the edema improve overnight? Venous edema is more likely than lymphedema to improve overnight. ${ }^{13}$

- Is there a history consistent with sleep apnea? Sleep apnea can cause pulmonary hypertension, which is a common cause of leg edema. ${ }^{4}$ Findings that may increase suspicion of sleep apnea include loud snoring or apnea noted by the sleep partner, daytime somnolence, or a neck circumference $>17$ inches.

\section{Physical Examination}

Key elements of the physical examination include

- Body mass index. Obesity is associated with sleep apnea and venous insufficiency. ${ }^{18-20}$

- Distribution of edema: unilateral leg edema is generally due to a local cause such as deep vein thrombosis, venous insufficiency, or lymphedema. Bilateral edema can be due to a local cause or systemic disease, such as heart failure or kid-
Note: The cause of leg edema is often multifactorial. Thus, more than one path in the algorithm may be relevant.

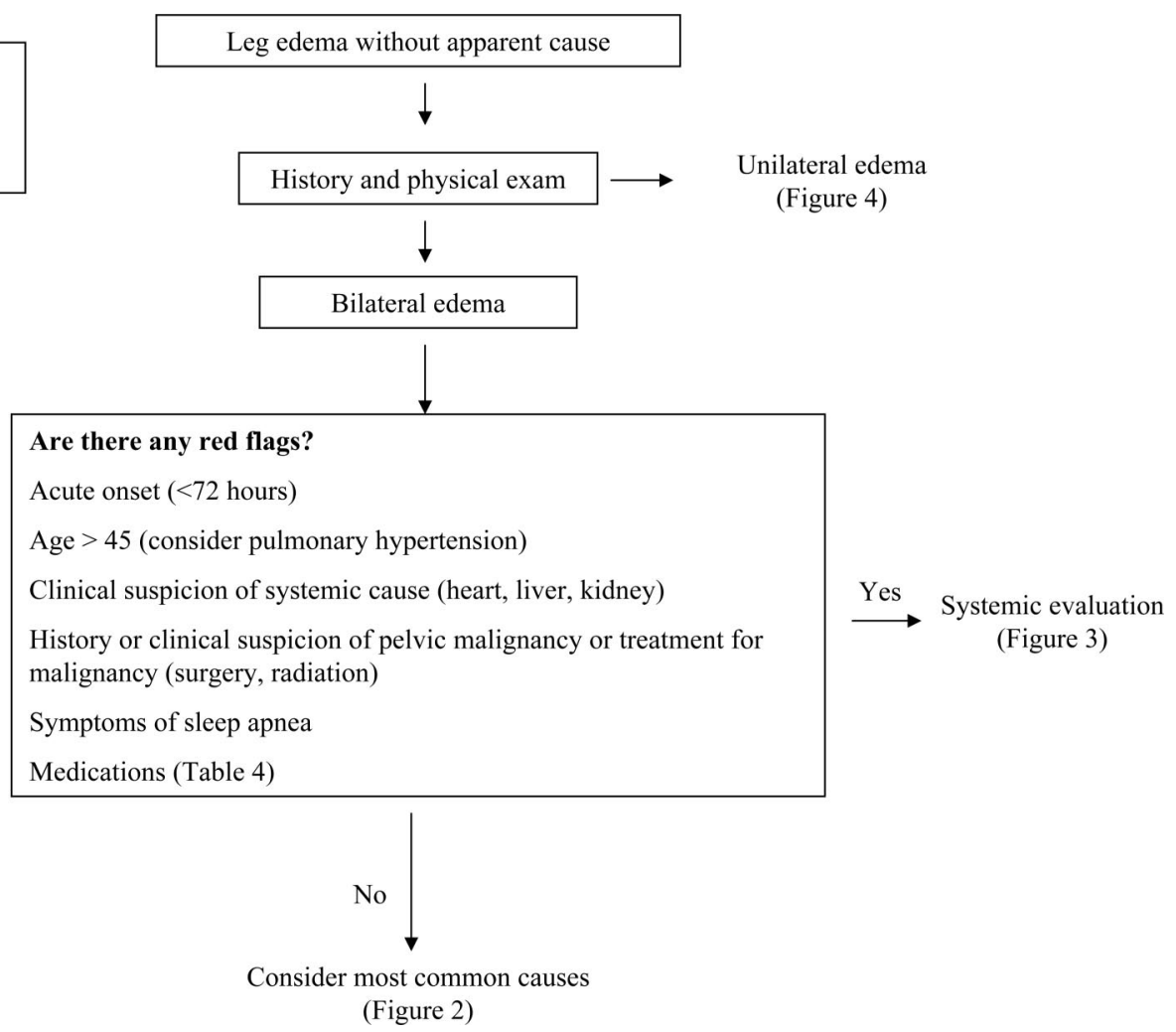

Figure 1. Algorithm for leg edema. 


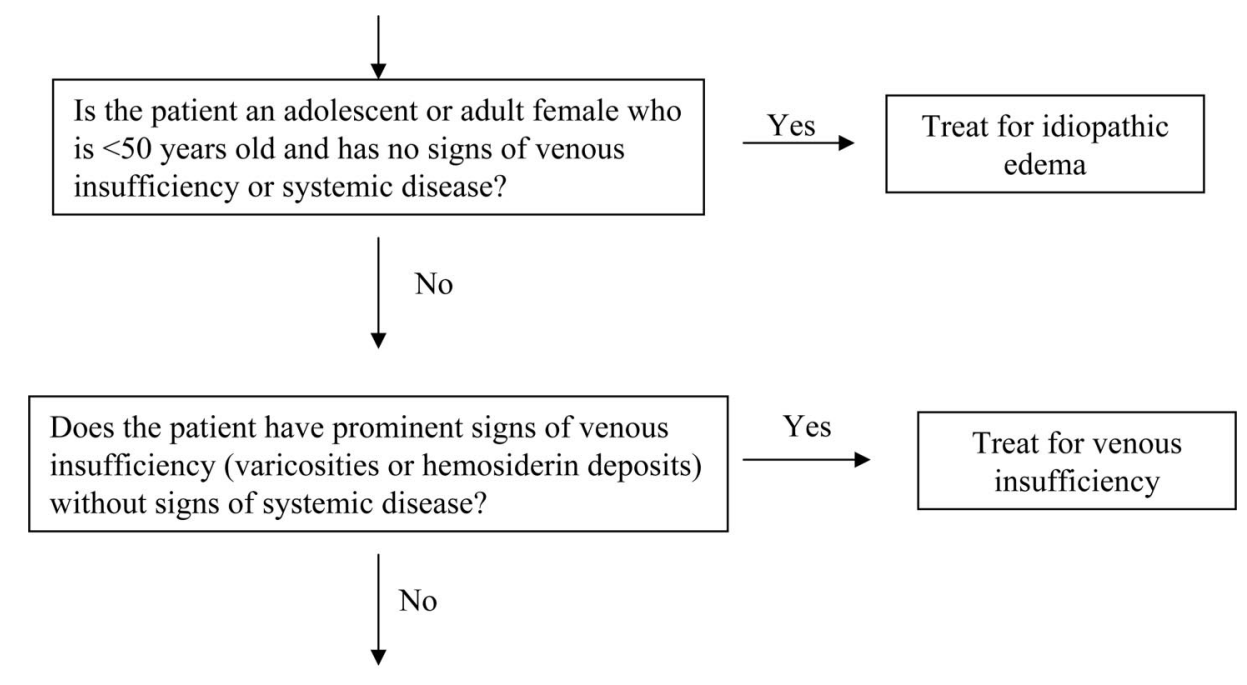

Evaluate for systemic cause (Figure 3)

Figure 2. Common causes.

ney disease. Generalized edema is due to systemic disease. The dorsum of the foot is spared in lipidema but prominently involved in lymphedema. ${ }^{8}$

- Tenderness: deep vein thrombosis and lipidema are often tender. Lymphedema is usually nontender.

- Pitting: deep vein thrombosis, venous insufficiency, and early lymphedema usually pit. Myxedema and the advanced fibrotic form of lymphedema typically do not pit. ${ }^{9,12,14,21}$

- Varicose veins: leg varicosities are often present in patients with chronic venous insufficiency, but venous insufficiency can occur without varicose veins. ${ }^{10}$

- Kaposi-Stemmer sign: inability to pinch a fold of skin on the dorsum of the foot at the base of the second toe is a sign of lymphedema. ${ }^{15,22}$

- Skin changes: a warty texture (hyperkeratosis) with papillomatosis and brawny induration are characteristic of chronic lymphedema. ${ }^{9,14}$ Brown hemosiderin deposits on the lower legs and ankles are consistent with venous insufficiency. Reflex sympathetic dystrophy initially leads to warm tender skin with increased sweating. Later the skin is thin, shiny, and cool. In the chronic stage, the skin becomes atrophic and dry with flexion contractures.

- Signs of systemic disease: findings of heart failure (especially jugular venous distension and lung crackles) and liver disease (ascites, spider heman- giomas, and jaundice) may be helpful in detecting a systemic cause.

\section{Diagnostic Studies}

Laboratory Tests

Most patients over age 50 with leg edema have venous insufficiency, but if the etiology is unclear, a short list of laboratory tests will help rule out systemic disease: complete blood count, urinalysis, electrolytes, creatinine, blood sugar, thyroid-stimulating hormone, and albumin. A serum albumin below $2 \mathrm{~g} / \mathrm{dL}$ often leads to edema and can be caused by liver disease, nephrotic syndrome, or protein-losing enteropathy. ${ }^{14}$ Additional tests are indicated depending on the clinical presentation:

- Patients who may have a cardiac etiology should have an electrocardiogram, echocardiogram, and chest radiograph. Dyspneic patients should have a brain natriuretic peptide (BNP) determination to help detect heart failure. The BNP is most helpful for ruling out (rather than ruling in) heart failure because the sensitivity is high $(90 \%){ }^{23}$

- Idiopathic edema can be diagnosed in young women without further testing if there is no reason to suspect another etiology based on history and physical examination. ${ }^{5}$ However, tests to confirm idiopathic edema have been described and may be helpful in difficult cases (Table 5). ${ }^{12,24}$ 


Systemic evaluation:
- complete blood count
- urinalysis
- clectrolytes
- blood sugar
- thyroid stimulating hormone
- albumin
- other tests for specific indications

\section{Specific indications:}

Acute edema: d-Dimer, follow with doppler exam if d-Dimer elevated OR clinical suspicion of DVT high

Age $>45$ years: echocardiogram to rule out pulmonary hypertension, heart failure

Suspicion of heart disease: ECG, echocardiogram, chest radiograph, brain natriuretic peptide

Suspicion of liver disease: ALT, AST, total bilirubin, alkaline phosphatase, prothrombin time, serum albumin

Suspicion of kidney disease: urinalysis with exam of sediment, serum lipids

Suspicion of malignancy: abdominal/pelvic CT scan

Suspicion of sleep apnea: sleep study, echocardiogram

Lymphedema: abdominal/pelvic CT scan

Medication known to cause edema (Table 4): consider reducing dose or changing medication

Figure 3. Systemic evaluation.

- In patients with acute edema ( $<72$ hours), a normal D-dimer will essentially rule out deep vein thrombosis if the clinical suspicion is low because false negative D-dimers are rare. ${ }^{25-27}$ However, an elevated D-dimer should be followed up with a Doppler examination because false positive Ddimers are common. ${ }^{28}$ The variability among laboratory assays has been problematic, but a recent systematic review recommended the rapid quantitative ELISA as the most useful test. ${ }^{25}$

- Patients with possible nephrotic syndrome should have serum lipids in addition to the basic laboratory studies listed above.

\section{Imaging Studies}

Patients over age 45 with edema of unclear etiology should have an echocardiogram to rule out pulmonary hypertension. ${ }^{4}$ Lymphoscintigraphy can be helpful to distinguish lymphedema from venous edema and to determine the cause of lymphedema. Lymphoscintigraphy is performed by injecting a radioactive tracer into the first web space and monitoring lymphatic flow with a gamma camera. ${ }^{13}$

\section{Common Causes of Leg Edema}

Venous Insufficiency

Venous insufficiency is characterized by chronic pitting edema, often associated with brown hemosiderin skin deposits on the lower legs. The skin changes can progress to dermatitis and ulceration, which usually occur over the medial maleoli. Other common findings include varicose veins and obesity. Most patients are asymptomatic but a sensation of aching or heaviness can occur. ${ }^{2}$ The diagnosis is usually made clinically but can be confirmed with a Doppler study. ${ }^{2,29}$ Although chronic venous insufficiency is thought to result from previous deep vein thrombosis, only one third 


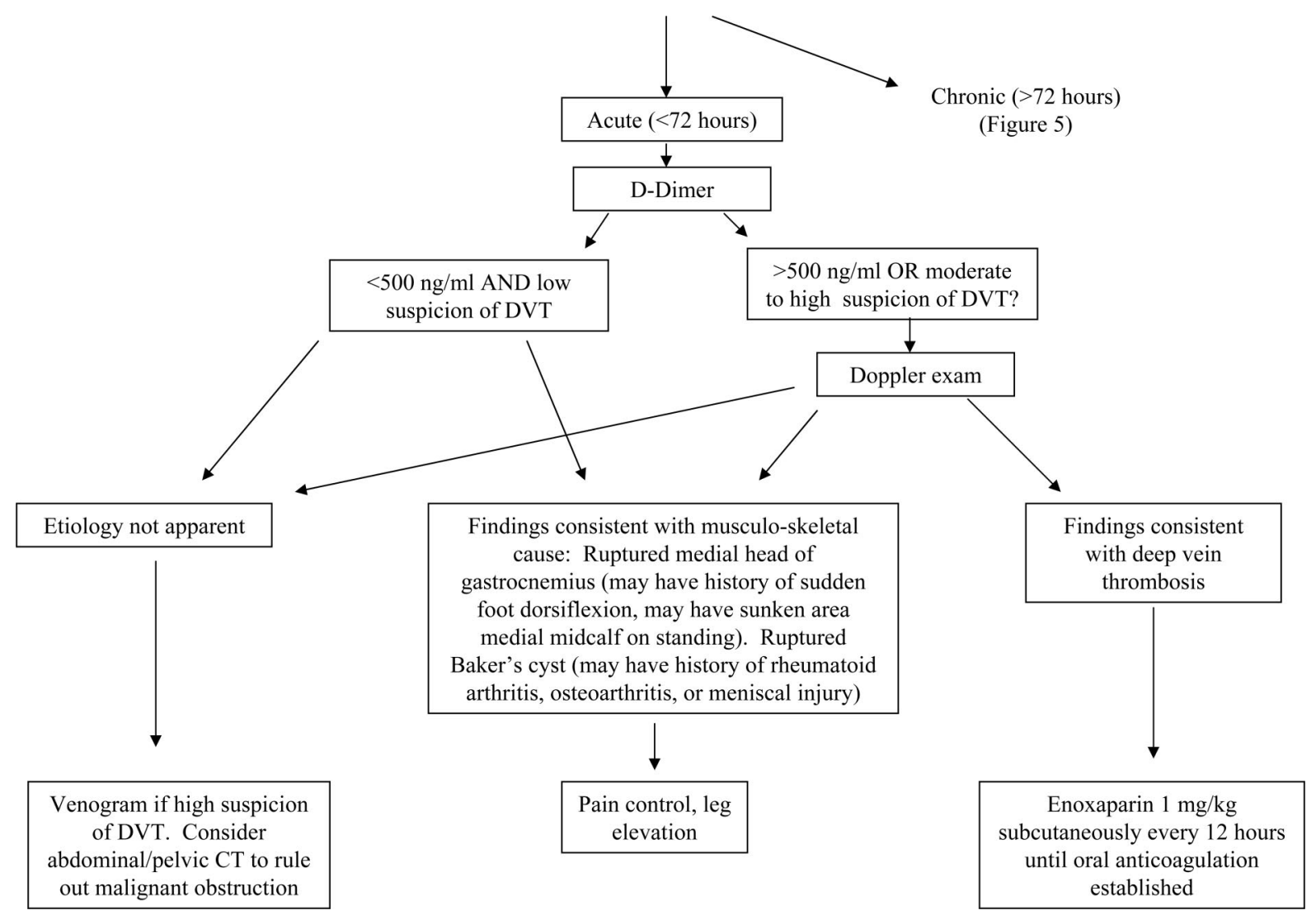

Figure 4. Unilateral edema.

of patients will give that history. "Dependent edema" is a variant of venous insufficiency and often occurs in patients following stroke who sit in wheelchairs for long periods.

\section{Heart Failure}

Patients with congestive heart failure complain of dyspnea, dependent edema, and fatigue. On physical examination they may have elevated jugular venous pressure, basilar crackles on chest auscultation, gallop rhythm, and pitting edema. In one study, BNP was found to be helpful in diagnosing heart failure among dyspneic patients. ${ }^{23}$ Using a cutoff value of $100 \mathrm{pg} / \mathrm{mL}$, this test had a sensitivity of $90 \%$ and specificity of $76 \%$ when compared with a clinical diagnosis by 2 independent cardiologists. ${ }^{23}$

\section{Pulmonary Hypertension}

Pulmonary hypertension commonly results from sleep apnea, is under-recognized as a cause of ede$\mathrm{ma},{ }^{4}$ and can be diagnosed by echocardiography. Other causes of pulmonary hypertension include left heart failure and chronic lung disease. In a study of primary care patients, Blankfield and colleagues ${ }^{4}$ obtained echocardiograms on 45 patients with edema. The initial clinical impression was venous insufficiency in $71 \%$ of these patients. However, the final impression was pulmonary hypertension $(>40 \mathrm{~mm} \mathrm{Hg}$ ) in $20 \%$ and "borderline pulmonary hypertension" (31 to $40 \mathrm{~mm} \mathrm{Hg}$ ) in $22 \%$. Only $22 \%$ of the patients were found to have venous insufficiency. This study was not designed to determine whether borderline pulmonary hypertension was the primary cause of edema or simply an incidental finding. Treating sleep apnea might improve the leg edema that results from pulmonary hypertension, but this also is unknown. Given these uncertainties, we recommend an echocardiogram in patients who are at risk for pulmonary hypertension and in patients over age 45 with leg edema of unclear etiology.

\section{Drugs}

Drugs that can cause edema are listed in Table 4. Calcium channel blockers and nonsteroidal antiinflammatory drugs (NSAIDS) are most commonly 


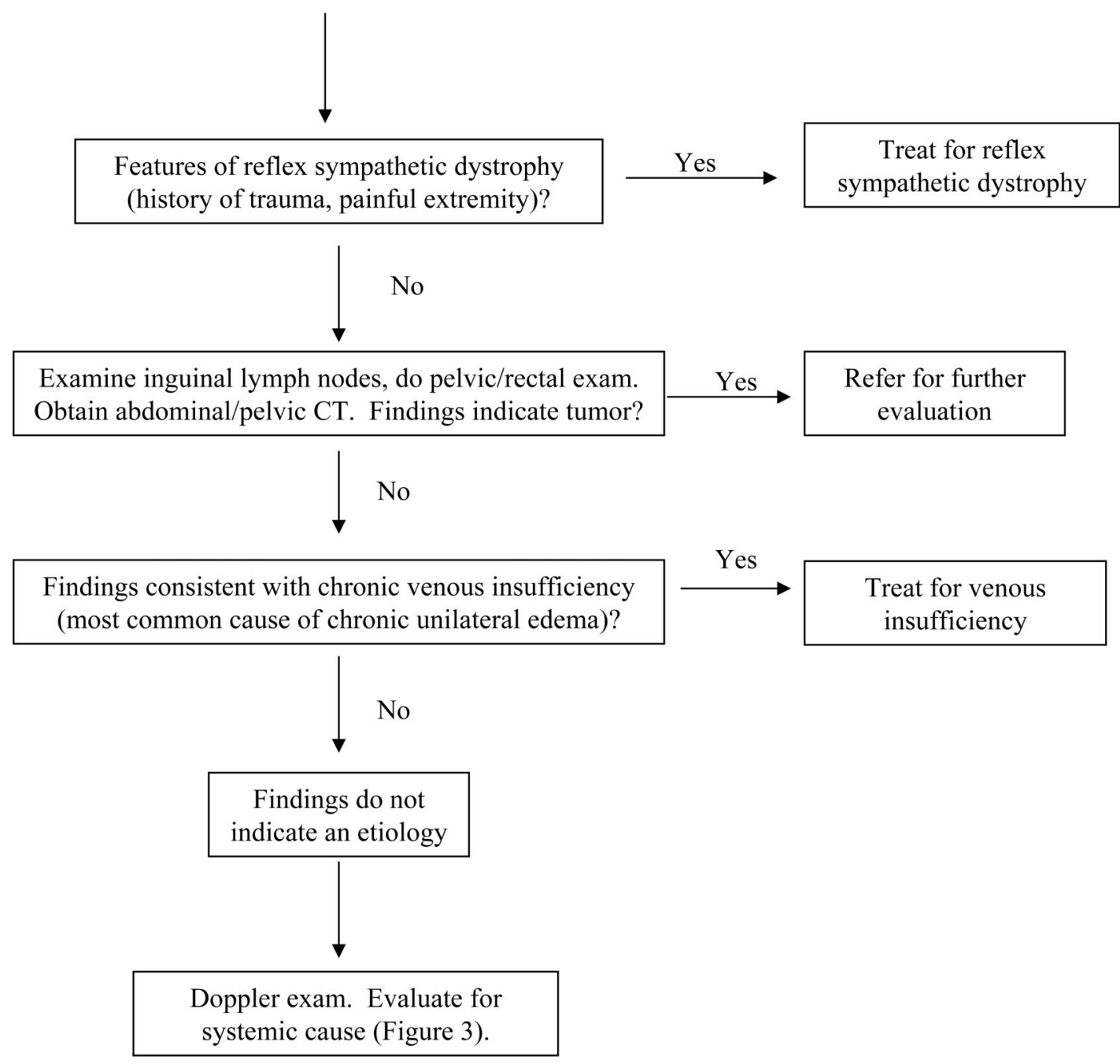

Figure 5. Chronic unilateral edema.

implicated. ${ }^{14}$ The incidence of edema in patients taking NSAIDS is approximately $5 \% .{ }^{17} \mathrm{Up}$ to $50 \%$ of patients on calcium-channel blockers develop

Table 4. Drugs That May Cause Leg Edema $9,12,14,16,17$

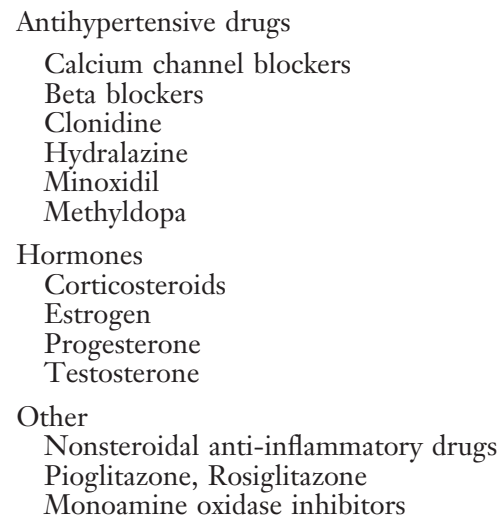

edema. ${ }^{13}$ Dihydropyridines (amlodipine, nifedipine) may be more likely to induce edema than phenylalkylamines (verapamil) or benzothiazepines (diltiazem). ${ }^{14}$

\section{Idiopathic Edema}

Idiopathic edema occurs only in menstruating women and is most common in the 20s and 30s. Synonyms include fluid-retention edema, orthostatic edema, cyclical edema, and periodic edema. However, the symptoms persist throughout the menstrual cycle, and idiopathic edema should be distinguished from premenstrual edema. Idiopathic edema leads to pathologic fluid retention in the upright position, and women typically notice a weight gain of $>1.4 \mathrm{~kg}$ as the day progresses. ${ }^{30}$ However, the weight gain may be as little as 0.7 $\mathrm{kg} .{ }^{31}$ Patients often complain of face and hand 
Morning and Evening Weights: Patients should weigh themselves nude and with an empty bladder before food or fluids in the morning and at bedtime. A mean weight gain $>0.7 \mathrm{~kg}$ is consistent with idiopathic edema.

Water Load Test: After avoiding diuretics for at least 10 days, the patient drinks $20 \mathrm{~mL} / \mathrm{kg}$ body weight (maximum $1500 \mathrm{~mL}$ ) uniced water over 20 minutes, sometime between 7:30 AM and 9:00 AM. The patient collects urine every hour, starting 1 hour before the oral fluid load and ending 4 hours after. On the first day, the patient should be walking slowly or standing during this 4-hour period. On the second day, the patient repeats the fluid load and urine collection, but should be recumbent during the 4-hour period. In patients with idiopathic edema, less than $55 \%$ of water load is excreted in the upright position and more than $65 \%$ in the recumbent position.

edema in addition to leg swelling. ${ }^{31}$ Several confirmatory tests are available (Table 5), but the diagnosis is usually made clinically after ruling out systemic disease by history and physical examination. ${ }^{31}$ The confirmatory tests in Table 5 are indicated only when there is significant doubt about the diagnosis. Obesity and depression can be associated with this syndrome, and diuretic abuse is common. $^{14}$

\section{Lymphedema}

Primary lymphedema is a rare disorder that is divided into 3 types according to age of presentation. ${ }^{21}$

Congenital lymphedema may be present at birth or becomes manifest by age 2 years. The familial form of congenital lymphedema is an autosomal dominant disorder known as Milroy disease.

Lymphedema praecox, the most common form of primary lymphedema, has its onset between age 2 and 35 and has a female to male ratio of 10:1. Lymphedema praecox is usually unilateral and is limited to the foot and calf in most patients. ${ }^{32}$ The familial form of lymphedema praecox is an autosomal dominant disorder known as Meige disease.

Lymphedema tarda presents after age 35 .

Secondary lymphedema is much more common than primary, and the cause is generally apparent from the history. The most common causes of leg lymphedema are tumor (eg, lymphoma, prostate cancer, ovarian cancer), surgery involving lymphatics, radiation therapy, and infection (bacterial infection or filariasis). ${ }^{21}$ Chronic lymphedema is usually distinguished from venous edema based on characteristic skin changes, absence of pitting, and history of an inciting cause. The skin becomes thickened and darkened and may develop multiple projections called lymphostatic verrucosis. ${ }^{9}$ The dorsum of the foot is prominently involved and may have a squared-off appearance. The examiner is unable to pinch a fold of skin on the dorsal aspect of the base of the second toe (Kaposi-Stemmer sign). ${ }^{12,14,22}$ However, early lymphedema may be difficult to distinguish from venous edema because pitting is present in both, and the skin changes are absent early in the course. If the distinction between early lymphedema and venous edema cannot be made clinically, lymphoscintigraphy may be indicated. ${ }^{33}$ However, the distinction cannot always be made because chronic venous insufficiency can lead to secondary lymphedema with abnormally delayed lymph drainage on lymphoscintigram. ${ }^{15,34}$

\section{Deep Vein Thrombosis}

Deep vein thrombosis classically results in an acutely swollen, painful leg that may be discolored. However, the presentation can be more subtle with mild, painless, asymmetric edema. The physical examination is often unreliable and patients with acute edema usually require further evaluation, which may include a D-dimer determination and a Doppler study (Figures 1-5). Risk factors for deep vein thrombosis include cancer, immobilization (especially following surgery or an injury), and a hypercoagulable state.

\section{Obesity}

Obesity itself does not cause leg edema but obesity can lead to many other causes such as chronic venous insufficiency, lymphedema, idiopathic edema, and obstructive sleep apnea.

\section{Premenstrual Edema}

Most women experience some premenstrual edema and weight gain. The edema tends to be generalized, occurs a few days before the beginning of menses, and resolves during a diuresis that occurs with the onset of menses. The etiology is poorly understood. ${ }^{35}$

\section{Pregnancy}

Increased venous pressure resulting from an enlarging uterus near term commonly leads to lower 


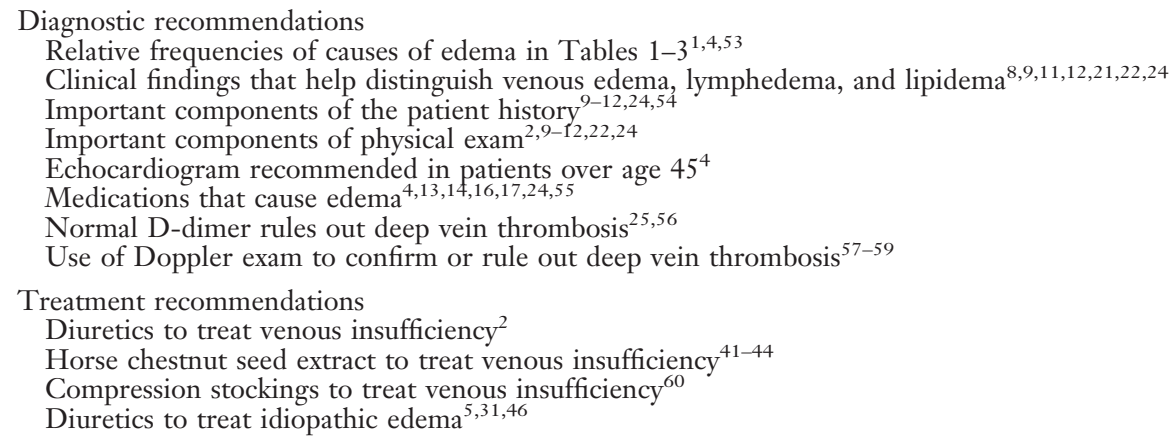

* Strength of recommendation classified according to the 3-component SORT system ${ }^{61}$ : A, denotes recommendation based on consistent and good-quality patient-oriented evidence ${ }^{61}$; B, denotes recommendation based on inconsistent or limited-quality patient-oriented evidence ${ }^{61}$; , denotes recommendation based on consensus, usual practice, opinion, disease-oriented evidence, or case series for studies of diagnosis, treatment, prevention, or screening. ${ }^{61}$

extremity edema and varicosities. Edema is commonly present in patients with preeclampsia but is no longer considered a factor in making the diagnosis. ${ }^{36}$

\section{Treatment}

\section{Venous insufficiency}

Chronic venous insufficiency is treated with leg elevation and knee-high compression stockings that provide 30 to $40 \mathrm{~mm} \mathrm{Hg}$ pressure at the ankle. ${ }^{2,37-40}$ If arterial insufficiency is a concern, an ankle-brachial index should be performed because compression stockings are contraindicated in arterial insufficiency. Patients who are refractory to compression stockings may improve with intermittent pneumatic compression pumps. ${ }^{2}$ Horse chestnut seed extract $(300 \mathrm{mg}$, standardized to $50 \mathrm{mg}$ of escin, twice a day) has been found to be effective in several studies and can be obtained in health food stores. ${ }^{41-44}$ Horse chestnut seed extract contains escin, which inhibits the activity of elastase and hyaluronidase. These enzymes are thought to play a role in the pathophysiology of chronic venous insufficiency. ${ }^{45}$ However, the benefits are modest and the agent has not gained widespread acceptance. Diuretics (eg, furosemide 20 to $40 \mathrm{mg}$ once a day with supplemental potassium) can be used for short periods in severely affected patients. However, venous insufficiency is not a volume overload state, and long-term use of diuretics can lead to adverse metabolic complications. ${ }^{2}$

\section{Idiopathic Edema}

Spironolactone is considered the drug of choice for idiopathic edema because of the secondary hyperaldosteronism found in patients with this disorder. ${ }^{31}$ The starting dose is 50 to $100 \mathrm{mg}$ daily (maximum $100 \mathrm{mg}, 4$ times daily). ${ }^{30,46}$ If spironolactone is not effective, low doses of a thiazide diuretic (eg, hydrochlorothiazide, $25 \mathrm{mg}$ daily) can be added with close monitoring of the serum potassium. It is best to avoid loop diuretics. ${ }^{30}$ The diuretic should be given in the early evening because fluid retention is most noticeable at the end of the day. Other measures include intermittent recumbency, avoiding environmental heat, low salt diet, avoiding excessive fluid intake, and weight loss for obese patients. ${ }^{31}$ It may be helpful to ask about depression, eating disorder, and surreptitious diuretic or laxative use. Compression stockings are usually not helpful and not tolerated. Many patients with idiopathic edema are already taking diuretics when first seen and may have "diureticinduced edema." ${ }^{46-48}$ Chronic use of diuretics may lead to a state of mild hypovolemia with resulting stimulation of the renin-angiotensin-aldosterone system. When the diuretics are withdrawn, a rebound worsening of edema occurs and patients believe they must continue. ${ }^{49}$ However, the treatment of suspected diuretic-induced edema is to withdraw diuretics for 3 to 4 weeks after warning the patient that her edema will probably worsen initially and reassuring her that the diuretic can 


\begin{tabular}{|c|c|}
\hline Question & Answer \\
\hline $\begin{array}{l}\text { Who needs a pelvic and rectal exam to } \\
\text { rule out tumor? }\end{array}$ & $\begin{array}{l}\text { We recommend a pelvic/rectal exam in patients who present with findings suspicious } \\
\text { for tumor, such as unilateral edema, pelvic symptoms, or weight loss. We were } \\
\text { unable to find evidence or published opinions on when the pelvic or rectal exam is } \\
\text { indicated in patients with edema The pelvic exam has poor sensitivity compared } \\
\text { with computed tomography (CT) scan for detection of pelvic tumors that cause leg } \\
\text { edema. However, information gained from this part of the exam may complement } \\
\text { subsequent radiologic studies. }\end{array}$ \\
\hline $\begin{array}{l}\text { Who needs an abdominal/pelvic CT } \\
\text { scan to rule out tumor? }\end{array}$ & $\begin{array}{l}\text { An abdominal/pelvic CT scan should be considered in patients over } 40 \text { without an } \\
\text { apparent cause for edema and in younger patients with suspicious findings (unilateral } \\
\text { edema, pelvic signs or symptoms, weight loss). Patients over age } 35 \text { with } \\
\text { undiagnosed lymphedema should have a CT scan. }{ }^{11} \text { Tumors commonly associated } \\
\text { with leg edema include prostate cancer, ovarian cancer, and lymphoma. }{ }^{11,12}\end{array}$ \\
\hline $\begin{array}{l}\text { Who needs to be evaluated for a } \\
\text { systemic cause, and what tests should } \\
\text { be done? }\end{array}$ & $\begin{array}{l}\text { It is reasonable to obtain a few basic tests in all patients with bilateral leg edema over } \\
\text { age } 45 \text { because the tests are relatively few and inexpensive. The basic tests include a } \\
\text { complete blood count, urinalysis, electrolytes, creatinine, blood sugar, thyroid- } \\
\text { stimulating hormone, and serum albumin. An echocardiogram should be considered } \\
\text { in patients over age } 45 \text {, because pulmonary hypertension is a common cause of leg } \\
\text { edema and is commonly missed. }{ }^{4} \text { Unilateral edema generally does not require a } \\
\text { search for a systemic cause. A search for liver disease is unnecessary in the absence } \\
\text { of ascites because leg edema is a late finding in patients with cirrhosis. }\end{array}$ \\
\hline $\begin{array}{l}\text { When should diuretics be used and } \\
\text { when should they be avoided? }\end{array}$ & $\begin{array}{l}\text { Loop diuretics (eg, furosemide, } 40 \mathrm{mg} \text { daily) should be used in patients with edema } \\
\text { secondary to heart failure or renal failure. }{ }^{62} \text { Patients with ascites and leg edema due } \\
\text { to cirrhosis should be treated with spironolactone (starting with } 50 \mathrm{mg} \text { daily) } \\
\text { combined with furosemide (starting with } 40 \mathrm{mg} \text { daily). }{ }^{63,64} \text { In patients with chronic } \\
\text { venous insufficiency, diuretics should be used only after leg elevation and } \\
\text { compression stockings have failed. At that point, they should be used sparingly and } \\
\text { for brief periods. In patients with idiopathic edema who are taking diuretics, a } 3 \text { to } 4 \\
\text { week trial off diuretics is indicated. In patients with idiopathic edema who are not } \\
\text { already taking diuretics or those who fail to improve off diuretics, spironolactone } \\
\text { and thiazides can be used. Long-term furosemide use in patients with idiopathic } \\
\text { edema has been associated with impaired renal function. }{ }^{65} \text { Diuretics should be used } \\
\text { rarely if at all in patients with lipidema, lymphedema, and deep vein thrombosis. }\end{array}$ \\
\hline
\end{tabular}

always be restarted. If the edema does not improve after 4 weeks, spironolactone can be initiated at a dose of 50 to $100 \mathrm{mg}$ daily and increased to a maximum of $100 \mathrm{mg}, 4$ times daily. ${ }^{30,46}$

\section{Lymphedema}

Nonspecific treatment of lymphedema includes exercise, elevation, compressive garments, manual lymphatic drainage, intermittent pneumatic compression, and surgery (excisional procedures, microsurgery). ${ }^{13,21,33}$ Tinea pedis should be controlled, and prophylactic antibiotics may be indicated for recurrent cellulitis. Diuretics are generally not helpful. ${ }^{13}$ Treatment of lymphedema is often disappointing, and psychosocial support is important in such patients.

\section{Deep Vein Thrombosis}

An acute deep vein thrombosis is generally treated with low molecular weight heparin, such as enoxaparin $1 \mathrm{mg} / \mathrm{kg} /$ dose subcutaneously every 12 hours. ${ }^{50}$ Warfarin can be initiated simultaneously with heparin, starting with 5 to $10 \mathrm{mg}$ daily for 2 days with subsequent dosage based on a target international normalized ratio range of 2.0 to 3.0. Heparin is continued for at least 5 days ( 10 days for severe iliofemoral thrombosis). When the international normalized ratio is between 2.0 and 3.0 for 2 days, the heparin can be withdrawn. A platelet count should be obtained on day 3 and day 10 of heparin therapy to rule out heparin-induced thrombocytopenia. The total duration of oral anticoagulation is reviewed elsewhere. ${ }^{50}$ If anticoagulation is contraindicated, an inferior vena cava filter may be an option. Thrombolytic agents are generally reserved for patients with phlegmasia cerula dolens, which is manifested by severe pain, bullae formation, and skin discoloration.

\section{Summary and Recommendations}

- In the approach to leg edema of unclear etiology, the physician should first rule out lipidema (fat 
maldistribution with sparing of feet) and lymphedema (marked foot and toe involvement, verrucous thickened skin, nonpitting when chronic) because subsequent evaluation and treatment are different for these disorders.

- If systemic disease is considered unlikely, the most common causes of bilateral leg edema are idiopathic edema (in young women) and chronic venous insufficiency (in older patients).

- In patients with chronic bilateral edema, the physician should consider the most common systemic causes (cardiac, renal, hepatic) and decide, based on history and physical examination, which of them need to be ruled out with further testing. Pulmonary hypertension is a common cause and should be suspected in patients who may have sleep apnea (eg, neck circumference $>17$ inches, loud snoring or apnea noted by sleep partner).

- If the patient presents with sudden onset $(<72$ hours) of leg swelling, a deep vein thrombosis should be ruled out using a Doppler examination.

- Evidence ratings for the major recommendations in this article are included in Table 6.

We are indebted to focus groups of faculty and residents at the University of Iowa Department of Family Medicine and the Moses Cone Hospital Family Medicine Residency for extensive review and comments, which were audiotaped, transcribed, and used to revise the manuscript.

\section{References}

1. Menzoain JO, Doyle JE. Venous insufficiency of the leg. Hosp Pract 1989;24:109-16.

2. Alguire PC, Mathes BM. Chronic venous insufficiency and venous ulceration. J Gen Intern Med 1997;12:374-83.

3. Kannel WB. Epidemiological aspects of heart failure. Cardiol Clin 1989;7:1-9.

4. Blankfield RP, Finkelhor RS, Alexander JJ, et al. Etiology and diagnosis of bilateral leg edema in primary care. Am J Med 1998;105:192-7.

5. Streeten DH. Idiopathic edema. Curr Ther Endocrinol Metab 1997;6:203-6.

6. Gorman WP, Davis KR, Donnelly R. ABC of arterial and venous disease. Swollen lower limb-1: general assessment and deep vein thrombosis. BMJ 2000;320:1453-6.

7. Mortimer PS. Swollen lower limb-2: lymphoedema. BMJ 2000;320:1527-9.

8. Rudkin GH, Miller TA. Lipidema: a clinical entity distinct from lymphedema. Plast Reconstr Surg 1994;94:841-7.

9. Ciocon JO, Fernandez BB, Ciocon DG. Leg edema: clinical clues to the differential diagnosis. Geriatrics 1993;48:34-40, 45.

10. Merli GJ, Spandorfer J. The outpatient with unilateral leg swelling. Med Clin North Am 1995;79:43547.

11. Young JR. The swollen leg. Clinical significance and differential diagnosis. Cardiol Clin 1991;9:443-56.

12. Yale SH, Mazza JJ. Approach to diagnosing lower extremity edema. Compr Ther 2001;27:242-52.

13. Topham EJ, Mortimer PS. Chronic lower limb oedema. Clin Med 2002;2:28-31.

14. Cho S, Atwood JE. Peripheral edema. Am J Med 2002;113:580-6.

15. Tiwari A, Cheng KS, Button M, Myint F, Hamilton G. Differential diagnosis, investigation, and current treatment of lower limb lymphedema. Arch Surg 2003;138:152-61.

16. Messerli FH. Vasodilatory edema: a common side effect of antihypertensive therapy. Curr Cardiol Rep 2002;4:479-82.

17. Frishman WH. Effects of nonsteroidal anti-inflammatory drug therapy on blood pressure and peripheral edema. Am J Cardiol 2002;89:18D-25D.

18. Padberg F Jr, Cerveira JJ, Lal BK, Pappas PJ, Varma $\mathrm{S}$, Hobson RW 2nd. Does severe venous insufficiency have a different etiology in the morbidly obese? Is it venous? J Vasc Surg 2003;37:79-85.

19. L'Hermitte F, Behar A, Paries J, Cohen-Boulakia F, Attali JR, Valensi P. Impairment of lymphatic function in women with gynoid adiposity and swelling syndrome. Metabolism 2003;52:805-9.

20. Ageno $W$, Piantanida E, Dentali F, et al. Body mass index is associated with the development of the postthrombotic syndrome. Thromb Haemost 2003;89: 305-9.

21. Szuba A, Rockson SG. Lymphedema: classification, diagnosis, and therapy. Vasc Med 1998;3:145-6.

22. Stemmer R. Ein klinisches zeichen zur gruhund differential diagnose des lymphodems. [A clinical symptom for the early and differential diagnosis of lymphedema]. German. Vasa 1976;5:261-2.

23. Maisel AS, Krishnaswamy P, Nowak RM, et al. Rapid measurement of B-type natriuretic peptide in the emergency diagnosis of heart failure. N Engl J Med 2002;347:161-7.

24. Powell AA, Armstrong MA. Peripheral edema. Am Fam Physician 1997;55:1721-6.

25. Stein PD, Hull RD, Patel KC, et al. D-dimer for the exclusion of acute venous thrombosis and pulmonary embolism: a systematic review. Ann Intern Med 2004;140:589-602.

26. Palareti G, Legnani C, Cosmi B, et al. Predictive value of $\mathrm{D}$-dimer test for recurrent venous thromboembolism after anticoagulation withdrawal in subjects with a previous idiopathic event and in carriers of congenital thrombophilia. Circulation 2003;108: $313-8$. 
27. Palareti G, Legnani C, Cosmi B, Guazzaloca G, Pancani C, Coccheri S. Risk of venous thromboembolism recurrence: high negative predictive value of D-dimer performed after oral anticoagulation is stopped. Thromb Haemost 2002;87:7-12.

28. Brotman DJ, Segal JB, Jani JT, Petty BG, Kickler TS. Limitations of D-dimer testing in unselected inpatients with suspected venous thromboembolism. Am J Med 2003;114:276-82.

29. Szendro G, Nicolaides AN, Zukowski AJ, et al. Duplex scanning in the assessment of deep venous incompetence. J Vasc Surg 1986;4:237-42.

30. Marks AD. Intermittent fluid retention in women. Is it idiopathic edema? Postgrad Med 1983;73:75-83.

31. Streeten DH. Idiopathic edema. Pathogenesis, clinical features, and treatment. Endocrinol Metab Clin North Am 1995;24:531-47.

32. Rockson SG. Lymphedema. Am J Med 2001;110: 288-95.

33. Mortimer PS. Managing lymphedema. Clin Exp Dermatol 1995;20:90-106.

34. Bull RH, Gane JN, Evans JE, Joseph AE, Mortimer PS. Abnormal lymph drainage in patients with chronic venous leg ulcers. J Am Acad Dermatol 1993;28:585-90.

35. Seippel L, Eriksson O, Grankvist K, von Shoultz B, Backstrom T. Physical symptoms in premenstrual syndrome are related to plasma progesterone and desoxycorticosterone. Gynecol Endocrinol 2000;14: 173-81.

36. Zlatnik FJ. Hypertension in pregnancy. The Iowa Perinatal Letter 2004;25:5-9.

37. Brandjes DP, Buller HR, Heijboer H, et al. Randomised trial of effect of compression stockings in patients with symptomatic proximal-vein thrombosis. Lancet 1997;349:759-62.

38. Ginsberg JS, Hirsh J, Julian J, et al. Prevention and treatment of postphlebitic syndrome: results of a 3-part study. Arch Intern Med 2001;161:2105-9.

39. Kolbach DN, Sandbrink MW, Hamulyak K, Neumann HA, Prins MH. Non-pharmaceutical measures for prevention of post-thrombotic syndrome. Cochrane Database Syst Rev 2004(1):CD004174.

40. Prandoni P, Lensing AW, Prins MH, et al. Belowknee elastic compression stockings to prevent the post-thrombotic syndrome: a randomized, controlled trial. Ann Intern Med 2004;141:249-56.

41. Rehn D, Unkauf M, Klein P, Jost V, Lucker PW. Comparative clinical efficacy and tolerability of oxerutins and horse chestnut extract in patients with chronic venous insufficiency. Arzneimittelforschung 1996;46:483-7.

42. Pittler MH, Ernst E. Horse chestnut seed extract for chronic venous insufficiency. Cochrane Database Syst Rev 2002(1):CD003230.

43. Pittler MH, Ernst E. Horse-chestnut seed extract for chronic venous insufficiency. A criteria-based systematic review. Arch Dermatol 1998;134:1356-60.
44. Diehm C, Trampisch HJ, Lange S, Schmidt C. Comparison of leg compression stocking and oral horse-chestnut seed extract therapy in patients with chronic venous insufficiency. Lancet 1996;347: 292-4.

45. Facino RM, Carini M, Stefani R, Aldini G, Saibene L. Anti-elastase and anti-hyaluronidase activities of saponins and sapogenins from Hedera helix, Aesculus hippocastanum, and Ruscus aculeatus: factors contributing to their efficacy in the treatment of venous insufficiency. Arch Pharm (Weinheim) 1995; 328:720-4.

46. Kay A, Davis CL. Idiopathic edema. Am J Kidney Dis 1999;34:405-23.

47. MacGregor GA, Markandu ND, Roulston JE, Jones JC, de Wardener HE. Is "idiopathic" edema idiopathic? Lancet 1979;1:397-400.

48. Idiopathic edema: role of diuretic abuse. Kidney Int 1981;19:881-91.

49. Rose BD. Idiopathic edema. Available from UpToDate.com. Accessed on 26 February 2005.

50. Lip GYH, Hull RD. Treatment of deep vein thrombosis. Available from www.UpToDate.com. Accessed on 5 November 2004.

51. Boyd DA. Unilateral lower extremity edema in MayThurner syndrome. Mil Med 2004;169:968-71.

52. Streeten DHP. Orthostatic disorders of the circulation. New York: Plenum Press; 1987.

53. Coon WW, Willis PW 3rd, Keller JB. Venous thromboembolism and other venous disease in the Tecumseh community health study. Circulation 1973;48:839-46.

54. Rose BD. Approach to the adult with edema. Available from UpToDate.com. Accessed 11 October 2004.

55. Niemeyer NV, Janney LM. Thiazolidinedione-induced edema. Pharmacotherapy 2002;22:924-9.

56. Bounameaux H, de Moerloose P, Perrier A, Reber G. Plasma measurement of D-dimer as diagnostic aid in suspected venous thromboembolism: an overview. Thromb Haemost 1994;71:1-6.

57. Lensing AW, Prandoni P, Brandjes D, et al. Detection of deep-vein thrombosis by real-time B-mode ultrasonography. N Engl J Med 1989;320:342-5.

58. Mattos MA, Londrey GL, Leutz DW, et al. Colorflow duplex scanning for the surveillance and diagnosis of acute deep venous thrombosis. J Vasc Surg 1992;15:366-75; Discussion 375-6.

59. Monreal M, Montserrat E, Salvador R, et al. Realtime ultrasound for diagnosis of symptomatic venous thrombosis and for screening of patients at risk: correlation with ascending conventional venography. Angiology 1989;40:527-33.

60. Partsch H. Compression therapy of the legs. A review. J Dermatol Surg Oncol 1991;17:799-805.

61. Ebell MH, Siwek J, Weiss BD. Strength of recom- 
mendation taxonomy (SORT): a patient-centered approach to grading evidence in the medical literature. J Fam Pract 2004;53:111-20.

62. Brater DC. Diuretic therapy. N Engl J Med 1998; 339:387-95.

63. Such J, Runyon BA. Initial therapy of ascites in patients with cirrhosis. Available from UpToDate. com. Accessed on 27 September 2004.
64. Fogel MR, Sawhney VK, Neal EA, Miller RG, Knauer CM, Gregory PB. Diuresis in the ascitic patient: a randomized controlled trial of three regimens. J Clin Gastroenterol 1981;3(Suppl 1): 73-80.

65. Shichiri M, Shiigai T, Takeuchi J. Long-term furosemide treatment in idiopathic edema. Arch Intern Med 1984;144:2161-4. 